\title{
BMJ Open Access to oxytocin and misoprostol for management of postpartum haemorrhage in Kenya, Uganda and Zambia: a cross-sectional assessment of availability, prices and affordability
}

\author{
Denis Kibira (D) , ${ }^{1,2}$ Gaby Isabelle Ooms, ${ }^{1,3}$ Hendrika A. van den Ham, ${ }^{1}$ \\ Juliet Sanyu Namugambe, ${ }^{4}$ Tim Reed, ${ }^{3}$ Hubert GM Leufkens, ${ }^{1}$ \\ Aukje Mantel-Teeuwisse (D) ${ }^{1}$
}

To cite: Kibira D, Ooms Gl, van den Ham HA, et al. Access to oxytocin and misoprostol for management of postpartum haemorrhage in Kenya, Uganda and Zambia: a cross-sectional assessment of availability, prices and affordability. BMJ Open 2021;11:e042948. doi:10.1136/ bmjopen-2020-042948

- Prepublication history for this paper is available online. To view these files, please visit the journal online (http://dx.doi. org/10.1136/bmjopen-2020042948).

Received 21 July 2020 Revised 09 December 2020 Accepted 17 December 2020

D Check for updates

(C) Author(s) (or their employer(s)) 2021. Re-use permitted under CC BY-NC. No commercial re-use. See rights and permissions. Published by BMJ.

For numbered affiliations see end of article.

Correspondence to

Denis Kibira; dkibira@gmail.com

\section{ABSTRACT}

Objective To assess access (availability and affordability) to oxytocin and misoprostol at health facilities in Kenya, Uganda and Zambia to improve prevention and management of postpartum haemorrhage (PPH).

Design The assessment was undertaken using data from Health Action International (HAl) research on sexual and reproductive health commodities based on a crosssectional design adapted from the standardised WHO/HAl methodology.

Setting Data were collected from 376 health facilities in in Kenya, Uganda and Zambia in July and August 2017.

Outcome measures Availability was calculated as mean percentage of sampled medicine outlets where medicine was found on the day of data collection. Medicine prices were compared with international reference prices (IRP) and expressed as median price ratios. Affordability was calculated using number of days required to pay for a standard treatment based on the daily income of the lowest paid government worker.

Results Availability of either oxytocin or misoprostol at health facilities was high; $81 \%$ in Kenya, $82 \%$ in Uganda and $76 \%$ in Zambia. 0xytocin was more available than misoprostol, and it was most available in the public sector in the three countries. Availability of misoprostol was highest in the public sector in Uganda (88\%). 0xytocin and misoprostol were purchased by patients at prices above IRP, but both medicines cost less than a day's wages and were therefore affordable. Availability of misoprostol was poor in rural settings where it would be more preferred due to lack of trained personnel and cold storage facilities required for oxytocin.

Conclusion Availability and affordability of either oxytocin or misoprostol at health facilities met the WHO benchmark of $80 \%$. However, countries with limited resources should explore mechanisms to optimise management of PPH by improving access to misoprostol especially in rural areas.

\section{BACKGROUND}

The risk of women dying due to pregnancy and childbirth remains a major global health

\section{Strengths and limitations of this study}

- The WHO/Health Action International methodology that was used for this study is tested, reliable, standardised and validated for the measurement of medicine prices and availability.

- The study provides details on availability, price and affordability of individual medicines across three sectors (public, private and mission).

- The methodology uses a cross-sectional design and therefore historical data trends were not traced.

- The study only used two frontline medicines for postpartum haemorrhage, while countries may have had other alternative therapies including carbetocin which were not captured.

- In Zambia, we surveyed 23 mission facilities which was below the 30 facilities per sector 30 recommended by the methodology.

challenge. In 2017, there were approximately 295000 maternal deaths globally, of which 94\% occurred in low-income and middleincome countries (LMICs). Sub-Saharan Africa contributed about $66 \%$ to these deaths. ${ }^{1}$ The global leading cause of maternal mortality is haemorrhage, accounting for $27 \%$ of all maternal deaths. ${ }^{2}$

Postpartum haemorrhage (PPH) which occurs after childbirth accounts for most $(72 \%)$ of the three forms of haemorrhage. Antepartum haemorrhage which occurs during pregnancy accounts for $24 \%$, while intrapartum haemorrhage (during childbirth) accounts for 3\%. ${ }^{2} \mathrm{PPH}$ is responsible for $34 \%$ of maternal deaths in Kenya, $25 \%$ in Uganda and $34 \%$ in Zambia. ${ }^{3-5}$

The WHO recommends oxytocin as the medicine of choice for management of PPH, and misoprostol as the second line alternative 
when injection capability is lacking and/or storage conditions for oxytocin are not met. Other uterotonics such as ergometrine and carbetocin are also recommended when the use of oxytocin is not feasible. ${ }^{1}$

The relevance of oxytocin and misoprostol to health systems was further emphasised by the United Nations Commission on Life-saving Commodities for women and children when they were listed among the 13 lifesaving, low-cost medicines with greatest proven potential to avert preventable deaths. ${ }^{6}$ Both oxytocin and misoprostol are included in national essential medicine lists in Kenya, Uganda and Zambia. ${ }^{7-9}$

The quality, efficacy and safety of oxytocin and misoprostol have been widely studied. ${ }^{10-23}$ Oxytocin is temperature sensitive and should therefore be stored under refrigeration at temperatures between $2^{\circ} \mathrm{C}$ and $8^{\circ} \mathrm{C}$ to prevent degradation expected at higher temperatures. ${ }^{10}$ Degradation reduces potency and consequently the effectiveness of the medicine. Oxytocin stability through the supply chain has proven a worry to policymakers and has been a subject of numerous investigations to ascertain quality and efficacy. ${ }^{11-13}$ Some studies on the quality of oxytocin found analysed samples to contain less active pharmaceutical ingredients than was claimed in the label, while some samples also failed sterility tests. ${ }^{14-16}$ LMICs with low resources may also lack facilities required for adequate storage conditions for oxytocin to ensure integrity of the product, while they may also lack trained health workers for its administration. ${ }^{17}$ Women living among displaced populations, in conflict areas, hard to reach areas, who deliver at home or with a traditional birth attendant seldom have access to a trained health worker. Hence, they do not have access to oxytocin or if they do, it is not safely used.$^{24}$ As a result of these challenges, prevention and treatment of PPH in low-resource settings using oxytocin has not provided the desired impact. ${ }^{1819}$

Misoprostol, a prostaglandin, is an alternative to oxytocin in the management of PPH. It is cheap, stable at room temperature and more convenient to administer. It can be administered sublingually, orally and vaginally. ${ }^{19} 202526$ It has been demonstrated through various studies that the use of misoprostol is feasible, improves uterotonic coverage, reduces incidence of PPH and that it is effective for use at community and household level in low-resource settings. ${ }^{20-22}$

In 2015, the WHO expert committee on the selection and use of medicines recommended the addition of misoprostol for the prevention and treatment of PPH when oxytocin is not available or cannot be used safely. ${ }^{23}$ At different occasions, the inclusion of misoprostol in the list of WHO recommended medicines was debated for both efficacy and safety reasons, but the 2015 decision to recommend misoprostol in addition to oxytocin for prevention of PPH was reaffirmed in 2019 by a WHO expert committee. ${ }^{27}$ Before 2015, misoprostol was indicated by WHO for use in induction of labour and management of spontaneous and induced abortion. ${ }^{28}$ The historical use of misoprostol for termination of pregnancies may have affected its acceptability for routine use in prevention of $\mathrm{PPH}$, despite available convincing evidence of its therapeutic effect and relative safety in management of $\mathrm{PPH}$. Another challenge is that the high doses of misoprostol required for postpartum haemorrhage often result in troublesome side effects such as vomiting and shivering. ${ }^{29}$ Furthermore, the longer half-life of the medicine means that it stays longer in the body and has potential to cause complications. ${ }^{30}$

These two medicines could be used complementarily to overcome challenges and barriers in policy, health sector infrastructure and health service delivery that at the moment inhibit the optimal management of PPH. ${ }^{241}$ However, there is a knowledge gap on the accessibility of both medicines in low-resource settings. This is a missed opportunity in closing the gap in the reduction of maternal mortality in developing countries. This paper therefore assesses access to oxytocin and misoprostol in urban and rural health facilities in Kenya, Uganda and Zambia through a cross-sectional assessment of availability, prices and affordability at the patient level of the two medicines to facilitate the optimal management of PPH.

\section{METHODS}

A secondary assessment of availability and prices of oxytocin and misoprostol was undertaken using data from Health Action International (HAI) research on sexual and reproductive health commodities (SRHC): Measuring Prices, Availability and Affordability. ${ }^{32}$ The data were collected in Kenya, Uganda and Zambia in July and August 2017 using a cross-sectional design with quantitative methods adapted from the standardised WHO/ HAI methodology, ${ }^{33}$ which has been validated ${ }^{34}$ and used extensively in several countries. ${ }^{35-37}$

\section{Patient and public involvement}

The research agenda for this study was set by the multistakeholder platform Medicines Transparency Alliance (MeTA) Councils in Kenya, Uganda and Zambia. The study protocols were reviewed and approved by MeTA Councils. Data collectors were selected from the membership of MeTA within the countries. Results were validated by stakeholders including civil society. Dissemination plans were made by MeTA councils and results were disseminated to wide country and intercountry platforms including Ministries of Health, Parliamentarians, private sector as well as civil society members to inform policy.

\section{Data collection}

For this study, the data on availability, price and affordability of the highest and lowest priced products of oxytocin $10 \mathrm{IU}, 1 \mathrm{~mL}$ injections and misoprostol $200 \mu \mathrm{g}$ tablets were extracted.

In each of the three countries, six geographical areas (districts, municipalities or counties) were selected; the country's main urban centre and five other areas which 
were randomly selected. All survey areas were reachable within 1 hour's travel from the country's main urban centre using a car or bus. Each survey area covered a population of between 100000 and 250000 people.

The WHO/HAI methodology prescribes a minimum of 30 health facilities from each of the sectors, that is, public, private and mission sectors, giving a minimum total of 90 facilities per country. ${ }^{33}$ In each survey area, the main public hospital was selected first. Then, eight public health facilities, four each from urban and rural areas, representing levels of care at which SRHCs should be made available, were randomly selected..$^{38}$ Additionally, eight private (for profit) and eight mission sector (not for profit) health facilities (four each from urban and rural areas) that were within a 3 hour drive radius of the main hospitals were selected. Thus, a total of 24 health facilities were sampled from each of the six survey areas in Kenya, Uganda and Zambia, respectively, giving a total of 144 facilities per country.

Eight data collectors with experience of conducting medicine surveys worked in pairs of a pharmacist and a social scientist under close supervision of a qualified survey manager. Prior to data collection, the team was trained on the methodology. Data collectors used a semistructured questionnaire administered to facility managers while physically ascertaining the availability of surveyed medicines. Availability was measured by the physical presence of a product in the outlet at the time of the survey. For each medicine surveyed, data collectors recorded the product name for both the highest and lowest priced medicines available, the manufacturer and unit price of the product. In the public sector in Uganda and Zambia where medicines are free of charge to care seekers, prices were not recorded.

Once data collection was complete, survey data were entered into a preprogrammed Microsoft Excel Workbook provided as part of the modified methodology. Data input was independently checked for errors. Additional quality control measures were executed at various stages throughout the study by a survey manager. The survey tools were pretested in Uganda in 2016 and a field test was conducted by all data collectors prior to data collection. Each data collection team had a supervisor who cross-checked the data on a daily basis for completeness, legibility and consistency and reported to the survey manager. Prior to data entry, all relayed data were checked for completeness and consistency.

\section{Data analysis}

The availability of oxytocin and misoprostol was calculated as the percentage of sampled medicine outlets where the medicine was found. Availability was also calculated for the presence of either oxytocin or misoprostol at a facility. Data were reported in aggregate as public, private or mission sector medicine outlets. Overall availability per sector was calculated as mean of the two medicines surveyed.
Patient prices were collected in local currency including Shillings in Uganda and Kenya, and Kwacha in Zambia. The mean, minimum and maximum unit prices were calculated. To facilitate cross-country comparisons, medicine prices obtained during the survey were expressed as ratios relative to a standard set of international reference prices (IRPs) by dividing the mean unit price (in dollars) by the Management Sciences for Health international buyers' reference unit price derived on 25 September $2018 .^{39}$ Mean price ratios (MPRs) were only calculated for oxytocin and misoprostol products that had price data from at least four medicine outlets per sector. ${ }^{33}$ The exchange rate used to calculate MPRs was 1 US $\$=102.67$ Kenya Shillings (KES), 1 US $\$=3667.9$ Uganda Shillings (UGX), 1 US $\$=8.85$ Zambia Kwacha (ZMW) taken on 1 July 2017 prior to the first day of data collection. ${ }^{40}$

Affordability was calculated using the number of days' wages it requires to pay for standard treatment or dose of treatment based on the daily income of the lowest paid government worker (LPGW) ${ }^{33}$ The daily wage of a LPGW is approximately KES 411 (US\$4) in Kenya, 6255 UGX (US\$1.78) in Uganda and ZMW 96.7 (US\$10.92) in Zambia, as per public service salary structures. ${ }^{42}$ Treatments that required more than 1 hour's wages to purchase were considered unaffordable. ${ }^{33}$

\section{RESULTS}

A total of 376 health facilities, including 120, 124 and 132 health facilities in Kenya, Uganda and Zambia, respectively, were surveyed as shown in figures 1 and 2.

\section{Availability across sectors}

Figure 1 shows the availability of either oxytocin or misoprostol at the surveyed health facilities in the three countries. Overall availability of either oxytocin or misoprostol met the WHO benchmark of $80 \%$ in Kenya (81\%) and Uganda (82\%) but was marginally lower in Zambia $(76 \%)$. Availability of oxytocin was higher than misoprostol except in Uganda. Availability of either oxytocin or misoprostol was comparable between the public and mission sectors.

In the public sector, the three countries met the WHO benchmark for availability of oxytocin. Misoprostol was only optimally available in the public sector in Uganda $(88 \%)$, with availability in Kenya and Zambia lower (36\% and $21 \%$, respectively). In the private sector, none of the countries met the WHO recommended availability for misoprostol. Availability in Zambia was especially low $(24 \%)$.

\section{Availability in urban versus rural areas}

Figure 2 shows availability in urban versus rural areas. Oxytocin was available in over $80 \%$ of all public urban and rural facilities across the three countries. Optimum availability of $80 \%$ was further achieved for oxytocin in Kenya mission urban facilities $(89 \%)$ and in Zambia's mission sector for both urban and rural facilities $(83 \%$ 


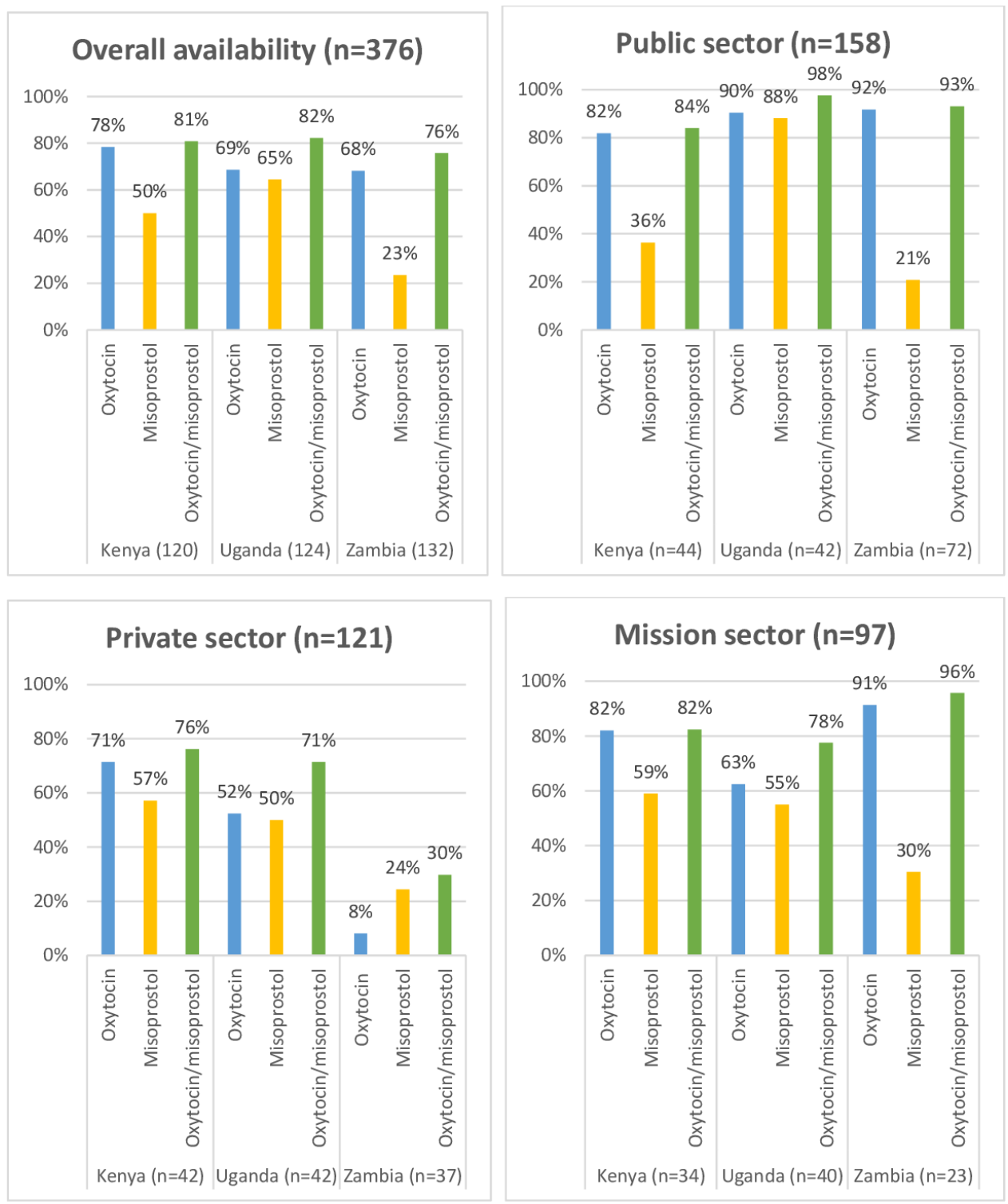

Figure 1 Availability of oxytocin and misoprostol across sectors in Kenya, Uganda and Zambia.

and $94 \%$, respectively). Optimum availability of misoprostol was only achieved in Ugandan public urban and rural facilities (90\% and $86 \%$, respectively).

In Kenya, oxytocin had a higher availability than misoprostol across all urban and rural facilities in the three sectors. Availability of misoprostol was lowest in the public sector: availability in urban facilities was $45 \%$, and $27 \%$ in rural facilities. In the private sector, there was a higher availability in rural facilities than in urban facilities for both oxytocin and misoprostol.

In Uganda, the public sector was optimally stocked with both oxytocin and misoprostol across urban and rural facilities. Rural public facilities had a higher availability of oxytocin than urban public facilities. In the private sector, rural facilities also had a higher availability of oxytocin and misoprostol compared with urban facilities.

Oxytocin had a high availability in Zambia's public and mission sectors across both urban and rural facilities. Availability in the private sector was very low. Availability of misoprostol was low across the sectors and areas, with highest availability found in urban mission facilities $(50 \%)$. Although both oxytocin and misoprostol were poorly available in the private sector, oxytocin was more available in rural than urban facilities, while misoprostol had a higher availability in urban facilities than in rural facilities.

\section{Prices and affordability}

Oxytocin and misoprostol were free for patients in the public and mission sectors in Zambia, and in the public sector in Uganda. In Kenya's public sector, the lowest price was noted for oxytocin, with a MPR of US\$ 0.174 (table 1). Both misoprostol and oxytocin cost less than a day's wages for an LPGW across all countries and sectors, and can therefore be considered affordable.

Notwithstanding the sectors in which the medicines were for free, the MPRs for oxytocin and misoprostol were above one in the countries, ranging from 1.37 for 

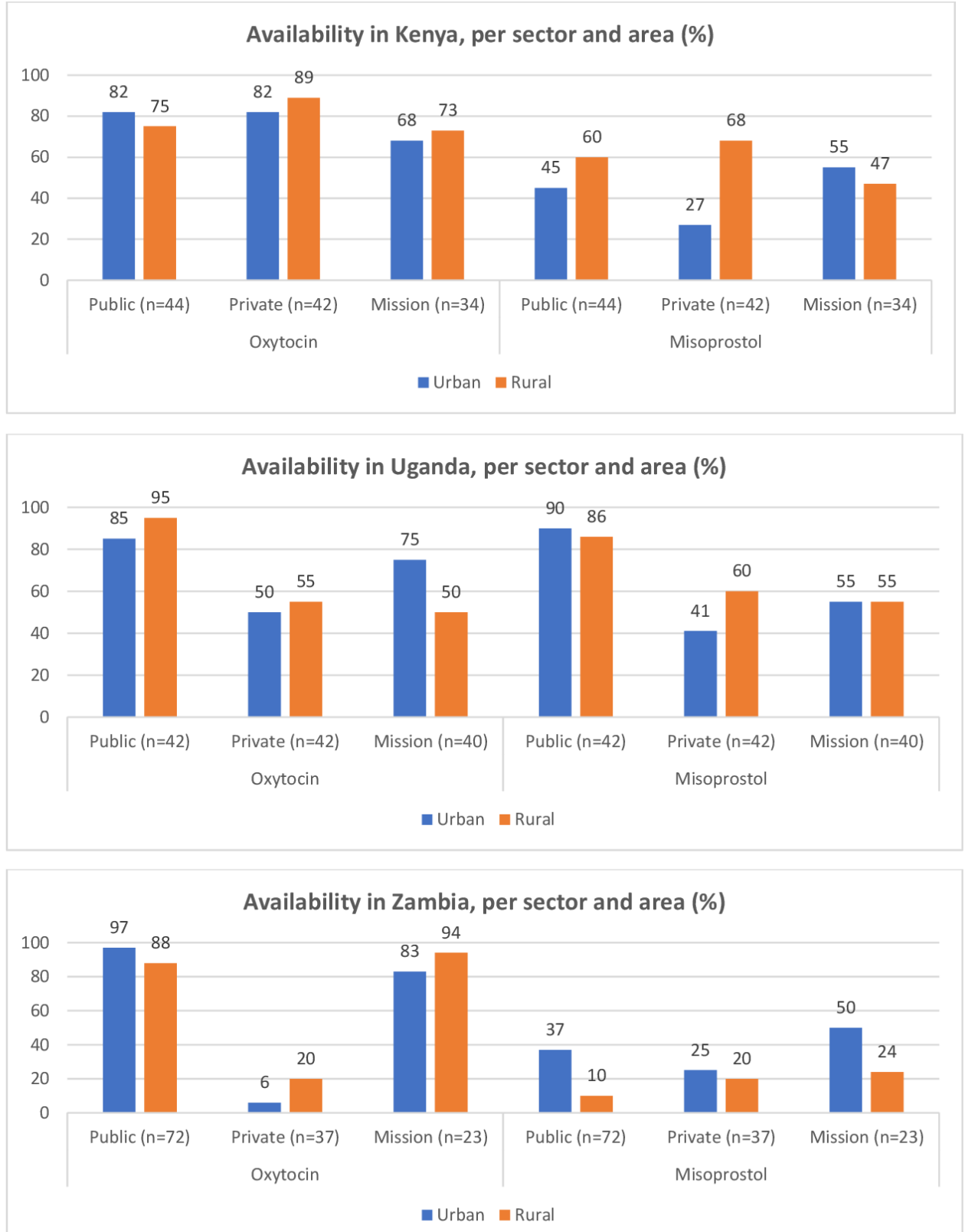

Figure 2 Availability of oxytocin and misoprostol in urban and rural facilities across countries.

Table 1 Prices and affordability of misoprostol and oxytocin across countries

\begin{tabular}{|c|c|c|c|c|c|c|c|c|c|c|}
\hline & & \multicolumn{3}{|c|}{ Public } & \multicolumn{3}{|c|}{ Private } & \multicolumn{3}{|c|}{ Mission } \\
\hline & & $\begin{array}{l}\text { Price } \\
\text { (US\$) }\end{array}$ & $\begin{array}{l}\text { Mean } \\
\text { price } \\
\text { ratio }\end{array}$ & $\begin{array}{l}\text { Affordability } \\
\text { of treatment } \\
\text { (number of day's } \\
\text { wages) }\end{array}$ & $\begin{array}{l}\text { Price } \\
\text { (US\$) }\end{array}$ & $\begin{array}{l}\text { Mean } \\
\text { price } \\
\text { ratio }\end{array}$ & $\begin{array}{l}\text { Affordability } \\
\text { of treatment } \\
\text { (number of day's } \\
\text { wages) }\end{array}$ & $\begin{array}{l}\text { Price } \\
\text { (US\$) }\end{array}$ & $\begin{array}{l}\text { Mean } \\
\text { price } \\
\text { ratio }\end{array}$ & $\begin{array}{l}\text { Affordability } \\
\text { of treatment } \\
\text { (number of day's } \\
\text { wages) }\end{array}$ \\
\hline \multirow[t]{3}{*}{ Kenya } & Oxytocin & 0.029 & 0.17 & 0.01 & 1.354 & 8.14 & 0.34 & 0.672 & 4.04 & 0.30 \\
\hline & Misoprostol & 0.273 & 1.37 & 0.07 & 1.967 & 9.84 & 0.49 & 1.217 & 6.09 & 0.17 \\
\hline & Oxytocin & 0 & NA & NA & 0.998 & 5.99 & 0.57 & 0.408 & 2.45 & 0.23 \\
\hline \multirow[t]{2}{*}{ Uganda } & Misoprostol & 0 & NA & NA & 0.589 & 2.95 & 0.34 & 0.39 & 1.95 & 0.22 \\
\hline & Oxytocin & 0 & NA & NA & 0.678 & 4.08 & 0.06 & NA & NA & NA \\
\hline Zambia & Misoprostol & 0 & NA & NA & 5.989 & 29.95 & 0.55 & NA & NA & NA \\
\hline
\end{tabular}

NA, not applicable; US\$, US dollar. 
misoprostol in Kenya's public sector to 29.95 for misoprostol in the private sector in Zambia. This meant that both misoprostol and oxytocin were accessed by patients at prices that were more expensive compared with IRPs.

\section{DISCUSSION}

This paper assesses access to oxytocin and misoprostol in urban and rural health facilities in Kenya, Uganda and Zambia through a cross-sectional assessment of availability, prices and affordability at the patient level of the two medicines to facilitate the optimal management of PPH.

Overall, availability of uterotonics, expressed as the presence of either oxytocin or misoprostol, was high in Kenya and Uganda, and just below the WHO benchmark of $80 \%$ in Zambia. Misoprostol was markedly less available than oxytocin. Oxytocin and misoprostol were accessed by patients in the private sector at prices that were more expensive than the IRPs. However, both medicines cost less than a day's wages, which is considered affordable. The availability of misoprostol across urban and rural areas did not show the expected pattern of having a higher availability of the medicine in rural areas, which are more prone to health system barriers for use of oxytocin.

Oxytocin availability was high in the public and mission sectors but lower in the private sector, particularly in Zambia. In the private sector, none of the countries met the WHO availability benchmark of $80 \%$ for the two medicines. Besides the public sector in Uganda, misoprostol was not optimally available in the other countries or sectors. Misoprostol had a low availability, particularly in rural areas where the medicine ought to play a major role given that facilities in these areas tend to lack adequately trained health workers and the health infrastructure required to maintain cold chain to safeguard the quality of oxytocin. ${ }^{17}$ Its poor availability in Kenya and Zambia may be a result of slow diffusion of the intervention into the health system. ${ }^{43}{ }^{44}$ Moreover, misoprostol has been recommended by WHO for use in PPH since 2015 after several rounds of weighing the benefits and risks, but the debate about its role in PPH prevention has continued over the years. ${ }^{23} 27$ The fear and stigma among health workers about the use of misoprostol to induce abortions may also have contributed to the situation. ${ }^{29}$ In contrast, Uganda's efforts as an early adaptor ${ }^{43} 44$ to ensure availability of misoprostol through government procurement and community level distribution strategies may explain why it has a higher availability of misoprostol, as well as lower PPH levels compared with Kenya and Zambia (25\% in Uganda vs $34 \%$ in both Kenya and Zambia). ${ }^{3-5}$

Urban facilities have better health infrastructure such as cold chain facilities, and also tend to have more health workers compared with rural facilities. ${ }^{45-47}$ It would therefore be expected that these urban areas would have a higher availability of oxytocin and lower availability of misoprostol than rural facilities. However, there were instances when rural facilities had a higher availability of oxytocin and a lower availability of misoprostol. This may indicate that stocking of oxytocin and misoprostol by health facilities does not take into consideration challenges faced by the facilities to administer the medicines. It will require more research in this area to better understand the data and for policy-makers to look into how to address context-specific barriers related to these medicines by ensuring that they are deployed where they can have maximum impact. ${ }^{48} 49$ For example, efforts should be made to deploy more misoprostol in rural areas where there is a lack of adequately trained personnel and a lack of health infrastructure to properly use oxytocin, and to ensure that both medicines are available to complement one another depending on circumstances.

PPH levels across the countries are high despite health facilities having reached the WHO benchmark for availability of either oxytocin or misoprostol across the three countries. This may confirm the finding from a study by Ononge et a $a \tilde{l}$ that despite the use of uterotonics, incidence of PPH remains high. It may be that some oxytocin found at health facilities may not have the quality and efficacy for optimum management of PPH. ${ }^{14-16}$ Countries should strive for universal access as the $80 \%$ availability benchmark by WHO still leaves one in five facilities without required medicine. However, availability of a medicine alone does not guarantee that it is used, health worker beliefs and knowledge as well as necessary infrastructure such as electricity and equipment are needed to reduce $\mathrm{PPH}$ levels.

Studies have shown that combinations of uterotonics have proven to be more effective. For example, a misoprostol plus oxytocin combination was found to be more effective in preventing PPH than the currently used standard of oxytocin only. ${ }^{50}$ This argument further emphasises that having both oxytocin and misoprostol available at the health facility could help to improve PPH management.

Although oxytocin and misoprostol were affordable to patients, the private sector prices were varied and more expensive compared with IRPs. For example, the MPR of misoprostol ranged from 1.37 in Kenya to 29.95 in Zambia. Therefore, even though availability met the WHO benchmark, individual patients may still be confronted with unavailability in the public sector, pushing them to seek care in the private sector where they may not be able to afford the prices of medicines. This suggests that countries need to explore pricing policies to improve affordability of the medicines.

The WHO/HAI methodology that was used for this study is tested, reliable, standardised and validated for the measurement of medicine prices and availability. ${ }^{34}$ The study provides details on availability, price and affordability of individual medicines across three sectors (public, private and mission). The methodology uses a cross-sectional design and therefore historical data trends were not traced. The study only used two frontline medicines for PPH, while countries may have had other alternative therapies including carbetocin which were not 
captured. The number of mission facilities surveyed in Zambia (23) was below the minimum (30) recommended for the methodology per sector. ${ }^{33}$ The findings presented here may not be used to predict country pharmaceutical supply chain but are intended to stimulate policy discussions on deliberate targeting and the use of available technologies to improve access.

\section{CONCLUSION}

Availability of oxytocin and misoprostol met the WHO benchmark in Kenya and Uganda but was just below the WHO benchmark in Zambia. In general, oxytocin was more available than misoprostol. Oxytocin and misoprostol were purchased by patients at prices above IRPs but both medicines cost less than a day's wages for a LPGW and were therefore considered affordable. However, there was no strategy in place that looked at which medicine could be best utilised in which area. Countries with limited resources should explore mechanisms to balance access to both oxytocin and misoprostol between rural and urban areas to optimise management of PPH.

\section{Author affiliations}

${ }^{1}$ Utrecht Centre for Pharmaceutical Policy and Regulation, Utrecht Institute for Pharmaceutical Sciences, Utrecht University, Utrecht, The Netherlands

${ }^{2}$ Coalition for Health Promotion and Social Development (HEPS-Uganda), Kampala, Uganda

${ }^{3}$ Health Action International, Amsterdam, The Netherlands

${ }^{4}$ Department of Pharmacy, Mbarara University of Science and Technology Mbarara, Mbarara, Uganda

Acknowledgements The authors acknowledge data collection teams in Kenya led by Dorothy Okemo, in Uganda led by Anthony Ssebagereka and in Zambia led by Liyoka Liyoka. We appreciate Dr Metin Gülmezoglu for providing comments and Daphne Ssebugwawo who edited the manuscript.

Contributors DK conceptualised the project, undertook data analysis and wrote the first draft of the manuscript; GOI contributed to data analysis; GIO, HAvdH, JSN-K, TR, HGML and AM-T revised the manuscript and critically reviewed its contents. GIO contributed to data analysis. AM-T critically reviewed the manuscript, provided comments and guidance on all drafts of manuscript.

Funding This research was funded by Health Action International through the Health Systems Advocacy Partnership.

Competing interests None declared.

Patient and public involvement Patients and/or the public were involved in the design, or conduct, or reporting or dissemination plans of this research. Refer to the 'Methods' section for further details.

Patient consent for publication Not required.

Ethics approval This study did not involve human subjects and did not involve direct interaction with patients and therefore ethical approval was not sought. However, Ministries of Health in Uganda and Zambia and Country Directors of Health in Kenya gave approval and provided introduction letters to health facilities.

Provenance and peer review Not commissioned; externally peer reviewed.

Data availability statement Data are available upon reasonable request. The data for this research can be availed upon request to the corresponding author or to Gaby Isabelle 0oms at Health Action International using email: Gaby@haiweb.org

Open access This is an open access article distributed in accordance with the Creative Commons Attribution Non Commercial (CC BY-NC 4.0) license, which permits others to distribute, remix, adapt, build upon this work non-commercially, and license their derivative works on different terms, provided the original work is properly cited, appropriate credit is given, any changes made indicated, and the use is non-commercial. See: http://creativecommons.org/licenses/by-nc/4.0/.
ORCID iDs

Denis Kibira http://orcid.org/0000-0002-6384-4273

Aukje Mantel-Teeuwisse http://orcid.org/0000-0002-8782-0698

\section{REFERENCES}

1 World Health Organization. Trends in maternal mortality: 2000 to 2017: estimates by who, UNICEF, UNFPA, world bank group and the United nations population division. Geneva: World Health Organization, 2019.

2 Say L, Chou D, Gemmill A, et al. Global causes of maternal death: a WHO systematic analysis. Lancet Glob Health 2014;2:e323-33.

3 PSI. Improving maternal health: preventing post-partum hemorrhage in Rural Zambia. Washington D.C: PSI, 2014.

4 Kinuthia K, Stephenson M, Maogoto E. Management of postpartum hemorrhage in a rural hospital in Kenya: a best practice implementation project. JBI Database System Rev Implement Rep 2019:17:248-58.

5 Ononge S, Mirembe F, Wandabwa J, et al. Incidence and risk factors for postpartum hemorrhage in Uganda. Reprod Health 2016;13:38.

6 United Nations, United Nations Commission on Life-saving Commodities for Women and Children. Commissioner's report. New York: United Nations, 2012.

7 Ministry of Health. Kenya essential medicines list 2016. Nairobi, Kenya: Ministry of Health, 2016.

8 Ministry of Health. Essentail medicines and health supplies list of Uganda. Kampala, Uganda, 2016.

9 Ministry of Health. Zambia essential medicines list. Lusaka: Ministry of Health, 2013.

10 World Health Organisation,. Recommendations for the prevention and treatment of postpartum haemorrhage. Geneva: Department of Reproductive Health, 2012.

11 de Groot AN, Hekster YA, Vree TB, et al. Oxytocin and desaminooxytocin tablets are not stable under simulated tropical conditions. $J$ Clin Pharm Ther 1995;20:115-9.

12 Hogerzeil HV, Battersby A, Srdanovic V, et al. Stability of essential drugs during shipment to the tropics. BMJ 1992;304:210-2.

13 Nazerali $\mathrm{H}$, Hogerzeil HV. The quality and stability of essential drugs in rural Zimbabwe: controlled longitudinal study. BMJ 1998:317:512-3.

14 Karikari -Boateng E. Post-market quality surveillance project maternal health care products on the Ghanaian market. Accra: Ghana Food and Drugs Authority, 2013.

15 Torloni MR, Gomes Freitas C, Kartoglu UH, et al. Quality of oxytocin available in low- and middle-income countries: a systematic review of the literature. BJOG 2016;123:2076-86.

16 Stanton C, Nand DN, Koski A, et al. Accessibility and potency of uterotonic drugs purchased by simulated clients in four districts in India. BMC Pregnancy Childbirth 2014;14:386.

17 Anyakora C, Oni Y, Ezedinachi U, et al. Quality medicines in maternal health: results of oxytocin, misoprostol, magnesium sulfate and calcium gluconate quality audits. BMC Pregnancy Childbirth 2018;18:44.

18 Hofmeyr GJ, Ferreira S, Nikodem VC, et al. Misoprostol for treating postpartum haemorrhage: a randomized controlled trial [ISRCTN72263357]. BMC Pregnancy Childbirth 2004:4:16.

19 Alfirevic Z, Blum J, Walraven G, et al. Prevention of postpartum hemorrhage with misoprostol. Int J Gynaecol Obstet 2007;99 Suppl 2:S198-201.

20 Smith JM, Baawo SD, Subah M, et al. Advance distribution of misoprostol for prevention of postpartum hemorrhage $(\mathrm{PPH})$ at home births in two districts of Liberia. BMC Pregnancy Childbirth 2014; $14: 189$.

21 McCormick MLet al. Averting maternal death and disability: prevention of postpartum haemorrhage in low resource settings. Int $J$ Obstet Gynaecol 2002;77:267-75.

22 Smith JM, Gubin R, Holston MM, et al. Misoprostol for postpartum hemorrhage prevention at home birth: an integrative review of global implementation experience to date. BMC Pregnancy Childbirth 2013;13.

23 World Health Organisation. The selection and use of essential medicines. Report of the WHO Expert Committee 2015(including the 19th WHO Model list of essentail medicines and the5th WHO Model list of essential medicines for children. Geneva: World Health Organisation, 2015.

24 Tran DN, Bero LA. Barriers and facilitators to the quality use of essential medicines for maternal health in low-resource countries: an Ishikawa framework. J Glob Health 2015:5:010406. 
25 Caliskan E, Dilbaz B, Meydanli MM, et al. Oral misoprostol for the third stage of labor: a randomized controlled trial. Obstet Gynecol 2003;101:921-8.

26 El-Refaey H, O'Brien P, Morafa W. Use of oral misoprostol in the prevention of postpartum haemorrhage. BJOG:An international journal of O\&G 1997;104:336-9.

27 World Health Organization. The selection and use of essential medicines 2019. Report of the 22nd who expert Committee on the selection and use of essential medicines, 1-5 April 2019. Geneva: World Health Organization, 2019.

28 Tang J, Kapp N, Dragoman M, et al. WHO recommendations for misoprostol use for obstetric and gynecologic indications. Int $J$ Gynaecol Obstet 2013;121:186-9.

29 Chong Y-S, Su L-L, Arulkumaran S. Misoprostol: a quarter century of use, abuse, and creative misuse. Obstet Gynecol Surv 2004;59:128-40.

30 Theunissen FJ, Chinery L, Pujar YV. Current research on carbetocin and implications for prevention of postpartum haemorrhage. Reprod Health 2018;15:94.

31 Jhpiego A. Brief: how can we increase global utilization of oxytocin for treatment of postpartum hemorrhage. Baltimore: Jhpiego, 2015

32 HAI. Sexual \& reproductive health commodities: measuring prices, availability \& affordability; methodology \& data entry manual. Amsterdam: HAI, 2017.

$33 \mathrm{WHO} / \mathrm{HAl}$. Measuring medicine prices, availability, affordability and price components. Geneva, Switzerland: WHO/HAl, 2008.

34 Madden JM, Meza E, Ewen M, et al. Measuring medicine prices in Peru: validation of key aspects of WHO/HAl survey methodology. Rev Panam Salud Publica 2010;27:291-9.

35 Cameron A, Mantel-Teeuwisse AK, Leufkens HGM, et al. Switching from originator brand medicines to generic equivalents in selected developing countries: how much could be saved? Value Health 2012;15:664-73.

36 Anson A, Ramay B, de Esparza AR, et al. Availability, prices and affordability of the World Health Organization's essential medicines for children in Guatemala. Global Health 2012;8:22.

37 Cameron A, Bansal A, Dua T, et al. Mapping the availability, price, and affordability of antiepileptic drugs in 46 countries. Epilepsia 2012;53:962-9.
38 Ministry of Health Uganda. Package of basic health services for Uganda. Kampala, Uganda: Ministry of Health Uganda, 1997.

39 Management Sciences for Health. International drug price indicator guide 2014 edition. Medford: MSH, 2015.

40 Bank of Uganda. Exchange rates, 2016. Available: https://www.bou. or.ug/bou/bouwebsite/ExchangeRates/

41 Oanda. Currency converter. Available: https://www.oanda.com/ currency/converter/ [Accessed cited 1st July 2017].

42 Ministry of Public Sevice Uganda. New salary structures for public servants for FY 2014/15. Kampala, Uganda: Ministry of Public Sevice Uganda, 2014.

43 Sharp BE, Miller SA. Potential for integrating diffusion of innovation principles into life cycle assessment of emerging technologies. Environ Sci Technol 2016;50:2771-81.

44 Gonzalez L, Aebersold M, Fenske CL. Diffusion of innovation: faculty barriers to adoption. Comput Inform Nurs 2014;32:201-4.

45 Henning-Smith C, Kozhimannil K, Casey M, et al. Rural-Urban differences in Medicare quality outcomes and the impact of risk adjustment. Med Care 2017;55:823-9.

46 Alhassan RK, Nketiah-Amponsah E. Frontline staff motivation levels and health care quality in rural and urban primary health facilities: a baseline study in the greater Accra and Western regions of Ghana. Health Econ Rev 2016;6.

47 Alghanem F, Clements JM. Narrowing performance gap between rural and urban hospitals for acute myocardial infarction care. Am J Emerg Med 2020;38:89-94.

48 Braddick L, Tuckey V, Abbas Z, et al. A mixed-methods study of barriers and facilitators to the implementation of postpartum hemorrhage guidelines in Uganda. Int J Gynaecol Obstet 2016;132:89-93.

49 Morris JL, Khatun S. Clinical guidelines-the challenges and opportunities: what we have learned from the case of misoprostol for postpartum hemorrhage. Int J Gynaecol Obstet 2019;144:122-7.

50 Gallos ID, Papadopoulou A, Man R, et al. Which drug is best for reducing excessive blood loss after birth. Cochrane Database Syst Rev 2018;4:413-5. 